\title{
Child oral health champion awarded CBE
}

Claire Stevens, a prominent advocate and champion for children's oral health has been appointed a CBE (Commander of the British Empire) in the Queen's New Year's Honours List in recognition of her commitment to improving oral health in children.

Stevens, an official spokesperson and immediate past President of the British Society of Paediatric Dentistry (BSPD), has been awarded the highest of the three orders of the British Empire, recognising the importance of children's dentistry, her work for the BSPD and the commitment she has shown to being an advocate for children's oral health.

Her profile was raised after the Faculty of Dental Surgery (of the Royal College of Surgeons of England) published a landmark report into the state of children's oral health ${ }^{1}$ in 2015 and the media sought a dentist with experience of treating extensive dental decay in children.

Stevens works as a Consultant in

Paediatric Dentistry in Greater Manchester's Health and Social Care Partnership, and she is also Chair of the Managed Clinical Network for Paediatric Dentistry in Greater

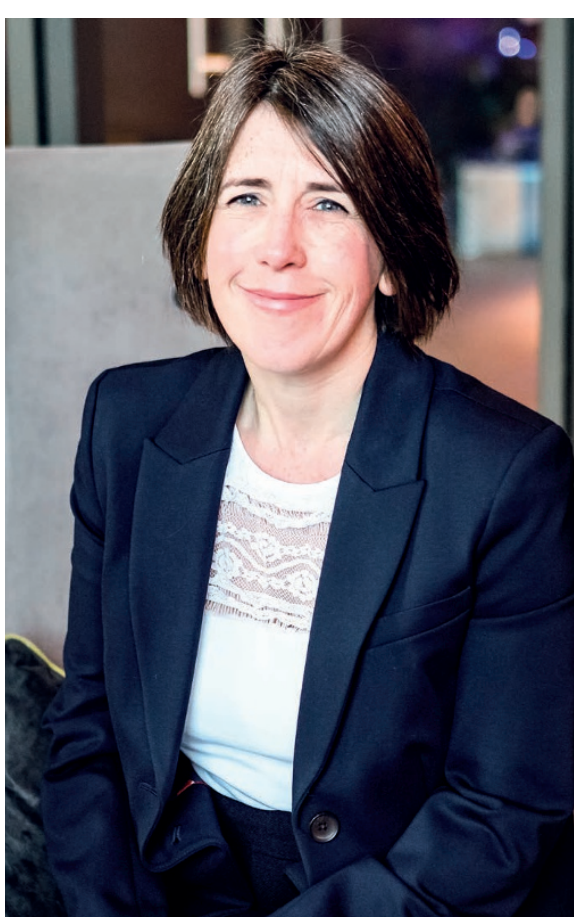

Manchester and an expert advisor to the Brush DJ app.

At Manchester University NHS

Foundation Trust, Stevens has taken a lead role in ensuring that the whole child's health and wellbeing is assessed, not just their teeth, signposting families onto other services and she has been instrumental in connecting her hospital with a programme designed to reduce obesity in Greater Manchester's children.

The founder of the Toothfairy blog (www. toothfairyblog.org), she has worked towards reversing the tide of general anaesthetics for multiple extractions in children.

Stevens said: 'This award feels momentous because it has been made for services to children's oral health. At last we are recognising the importance of supporting every child to grow up free of dental disease.

'I am the public face of the campaign to improve children's oral health, but this isn't just about me. Others have smoothed the way, and I am privileged to work alongside many people who continue to dedicate their lives to improving children's health. My advocacy has only worked thanks to all those who collaborate and work with me, in BSPD, in Greater Manchester and within the profession. To them I pay tribute.'

1. Royal College of Surgeons of England. The state of children's oral health in England. 2015. Available at https://www.rcseng.ac.uk/library-and-publications/ rcs-publications/docs/report-childrens-oral-health/ (accessed January 2019).

\section{Drop in counterfeit dental device seizures}

There has been a steady fall in the number of seizures of counterfeit dental and medical devices but industry is keen to maintain close scrutiny of this potentially dangerous issue, according to the industry representative body the British Dental Industry Association (BDIA).

In its latest edition ${ }^{1}$ of Spotlight - the annual statistical digest - the BDIA said that it maintained its close relationship with the Medicines and Healthcare products Regulatory Agency (MHRA) in tackling counterfeit and non-compliant dental devices.

According to MHRA data, seizures of counterfeit and non-compliant dental devices fell from 12,122 between January 2014 and March 2015 (worth $£ 100,000$ ) to just 456 seizures between March 2017 and April 2018 (worth $£ 7,460$ ).

The body said it was committed to the Counterfeit and Substandard Instruments and Devices Initiative (CSIDI) launched in 2014 as a way to educate dental professionals about the dangers for themselves, patients and staff of buying and using such equipment.

The BDIA said: 'Whilst the CSIDI campaign has significantly raised awareness of the issue and seizure figures have reduced, the purchase and use of counterfeit and non-compliant dental equipment remains a clear and present danger.'

The dental industry was still concerned, said the BDIA, with the 'growing sophistication' of the counterfeit and non-compliant dental devices that were being seized by the MHRA as well as the prevalence of online sellers offering such devices.

Ongoing efforts to deal with the problem included close collaboration with the BDA, the GDC, NHS England and the Care Quality Commission as well as dental defence bodies.
Also in the new edition of Spotlight, the BDIA reported on the findings of a buyer behaviour survey it carried out last year, which gathered 375 responses from dental team members.

It showed that more than two thirds (69\%) of survey respondents preferred ordering dental consumables via an online dental dealer.

Around a third (30\%) said they were highly influenced by price, relative to competitors when choosing a particular product, compared to $23 \%$ influenced by special offers and discounts.

Similarly, 39\% of survey respondents said they were highly influenced by price compared to competitors when choosing their main supplier for purchasing the majority of their products.

British Dental Industry Association. Spotlight 2018. 2019. Available at https://www.bdia.org.uk/dental/ resources/spotlight (accessed January 2019). 